\title{
Does the integration of environmental impact assessment and mine closure planning deliver effective mine closure plans in Western Australia?
}

\author{
R Getty SRK Consulting (Australasia) Pty Ltd, Australia
}

A Morrison-Saunders Edith Cowan University, Australia; North West University, South Africa

\begin{abstract}
Environmental impact assessment (EIA) and mine closure planning became formally integrated in Western Australia in 2011 when amendments to the Mining Act 1978 resulted in the requirement of a mine closure plan (MCP) to be submitted by proponents along with their EIA documents. This procedural innovation aimed to force early consideration of mine closure in line with international best practice and raise the level of closure planning compliance. Internationally, it is generally held that early closure planning will reduce costs and improve closure outcomes thereby reducing financial, environmental and social liabilities.

This paper presents the results of the first study to explore the integration of EIA and mine closure planning in Western Australia and consider the extent to which such integration facilitates effective MCPs at the project approval stage. The opinions of twelve experienced EIA and/or mine closure professionals, representing regulators and proponents alike, were obtained from semi-structured interviews. Thematic analysis used both top down and bottom up approaches to identify recurring themes and novel concepts. Overall both regulators and proponents were found to be strongly supportive of the integration of EIA and the potential of early planning to improve mine closure outcomes, particularly with regard to the identification and reduction of risk. However, opinions were divided about the influence of integration on the effectiveness of early MCP or if the current Western Australian 'Guidelines for Preparing Mine Closure Plans' are capable of delivering effective early MCP. The responses suggest that although the current regulatory framework exists to drive integration that could enable effective MCP at the project assessment and approval stage, the most important factor is the motivation of key facilitators to pursue good outcomes. Opportunities to enhance the current framework lie in increasing transparency, expanding aspects of the guidance and ensuring enforcement of the commitments made in mine closure plans.
\end{abstract}

Keywords: environmental impact assessment, mine closure planning, integration, effectiveness

\section{$1 \quad$ Introduction}

This research was motivated by an interest in exploring how the integration of environmental impact assessment (EIA) and mine closure planning activities might be realised during the approval stage for new mining proposals in order to deliver effective mine closure plans (MCPs). EIA and mine closure planning have many goals and procedures in common such as identifying and assessing the environmental and social impacts of mining, putting in place appropriate mitigation, management and monitoring measures to address these impacts and consulting interested and affected parties (e.g. Otto 1997; Sánchez et al. 2014; Morrison-Saunders et al. 2016). Both involve the evaluation of dynamic natural processes which are often complex with poorly understood interrelationships and often limited baseline data for greenfield proposals, with an assessment process that takes place in a typically convoluted regulatory setting involving multiple stakeholders and individuals (Haymont 2012; Environment and Communications References Committee 2019). Both are intended to commence as early as possible and continue throughout the lifecycle, employ adaptive management to maximise performance in unpredictable environments, and support sustainable development (International Association for Impact Assessment [IAIA] 1999; Kwasniak 2010; Department of 
Industry, Innovation and Science [DIIS] 2016; Bond \& Morrison-Saunders 2018; International Council on Mining and Metals [ICMM] 2019). Transparency is important for accountability and to allow external evaluation of the validity of process and provision (Morrison-Saunders \& Bailey 2000; McHenry et al. 2015; Environment and Communications References Committee 2019). Perhaps unsurprisingly the similarities between EIA and mine closure planning lead Morrison-Saunders et al. (2016) to remark that: "As such, the two processes should proceed hand in hand" (p. 118) and we were keen to explore how the two processes might be integrated in practice.

A dictionary definition of integration is "to combine two or more things in order to become more effective" (Cambridge dictionary, retrieved from https://dictionary.cambridge.org/dictionary/english/integration). In the context of mining and impact assessments, integration can also refer to the sharing of common tasks to reduce duplication of effort and improve efficiency (Scrase \& Sheate 2002; Sánchez \& Hacking 2002; van Asselt 2000; Canter \& Atkinson 2010; Sánchez et al. 2014). Guidance recently published by the ICMM (2019) emphasise the importance of an integrated framework for mine closure planning and we unpack the notion of integration in the context of EIA and mine closure planning later on.

Western Australia where this study is based is the second most attractive jurisdiction in the world for mining investment when considering mineral and policy perception according to the Frasier Institute Annual Report (Steadman \& Green 2018). The desire in Western Australia to enhance the efficiency and effectiveness of mine closure planning through a fundamentally integrated approach is evident from the Guidelines for Preparing Mine Closure Plans (the 'Guidelines') (Department of Mines and Petroleum \& Environmental Protection Authority [DMP \& EPA] 2015) which were first published in 2011 following the legislative innovation that bestowed legal status upon them. The collaborative effort by the lead agencies for administering EIA and MCP, the EPA and the Department of Mines and Petroleum (DMP - now the Department of Mines, Industry Regulation and Safety or DMIRS) respectively is supported by a Memorandum of Understanding (MoU) between them and described in the EIA Procedures Manual (EPA 2018). The collaboration between DMIRS and the EPA is not new and long-standing measures to cooperate during EIA have been accomplished through mechanisms such as the $2009 \mathrm{MoU}$ regarding the referral of Mineral and Petroleum Onshore and Offshore and Geothermal Proposals (DMP \& EPA 2009).

The purpose of this research was to explore how the integration of EIA and mine closure planning can help achieve effective MCP at the project approval stage. Integration became a regulatory requirement following relatively recent amendments to the Mining Act 1978 which came into effect in 2011. The amendments had two aims, to ensure early and transparent consideration of mine closure in line with international best practice and reduce financial risk to the state (Minister for Mines and Petroleum 2012). The changes require an MCP to be submitted with documents required by the EPA for the EIA of mining developments likely to have a significant impact on the environment (DMP \& EPA 2015, p. 4). Section 70 of the Mining Act also requires an approved MCP with every mining proposal application. This research was specifically designed to explore the effectiveness of this integrated approach to mine closure planning during the early phases of project design, assessment and approval as we explain in the next section.

\section{Methodology}

Before providing details of our study design and methodology, we acknowledge that it can be reasonably argued that it is not possible to determine the extent to which mine closure planning is effective at the project approval stage. This is because effectiveness might normally be considered to be the achievement of objectives (Kolhoff et al. 2009) which will only be realised much later. In the mine closure framework of Western Australia, objectives are defined by completion criteria and when met and approved by government this theoretically allows tenure to be relinquished (DMP \& EPA 2015). Only a handful of mines have been relinquished in Australia with most mines entering a phase of care and maintenance phase instead (Environment and Communications References Committee 2019). While several mine sites are in the final stages of rehabilitation, the only mine to be completely relinquished in Western Australia that we are aware of is the Bottle Creek Mine in 2001 (DIIS 2016), although reports suggest that this mine may be back in production within two years (Nichols 2019). It is thus not possible to evaluate effectiveness of the integrated 
approach to mine closure planning by means of case studies where completion has been realised. Instead, we designed our research around the perceptions of key stakeholders involved in the early stages of EIA and mine closure planning in Western Australia.

Semi-structured interviews were designed to explore the views of industry professionals experienced in EIA and/or mine closure planning. Participants were recruited by convenience and snowball sampling (referrals during the interview process). Although the small, opportunistic sample is not expected to be representative of the wider community of EIA and mine closure practitioners in Western Australia, it is suitable for a highlevel exploratory investigation of this kind. Analysis of knowledge saturation from qualitative interviews indicate that $80-92 \%$ of themes can be revealed within 12 interviews, based on detailed literature reviews of qualitative interviews and simulation studies (e.g. Guest et al. 2006; Namey et al. 2016), although the heterogeneity of the sample group and the interview questions are important modifying factors to consider (Guest et al. 2006).

Instead of using relinquishment as a standard of effectiveness as this is elusive to date, this research has considered effectiveness to be the efficient alignment of mine closure planning with Australian and international best practice literature, including the Australian Government's, Leading Practice Sustainable Development Program for the Mining Industry (DIIS 2016) and the recently published Integrated Mine Closure Good Practice Guide from the ICMM (2019).

A series of open-ended questions (Table 1) were structured to explore our research aim and supplemented by unscripted probing questions to stimulate further discussion in the interviews that may not have been previously considered (Leech 2002; Saunders et al. 2009). This resulted in a free-flowing conversation rather than the 'linear' sequence of questions implied by the following list of questions we explored:

- How influential is EIA to mine closure planning and vice versa at the project approval stage?

- How do you view the integration of EIA and MCP?

- How do you think mine closure planning can be effective at the project approval stage?

- Can you think of any advantages or issues with the integration of EIA and MCP?

- How do you think the integration of EIA and mine closure planning facilitates effective MCP at the project approval stage?

Table $1 \quad$ Number of interviews per professional role

\begin{tabular}{lc}
\hline Profession & No. of interviews \\
\hline Regulator & 4 \\
Consultant & 4 \\
Corporate environmental managers & 3 \\
Site environmental managers & 1 \\
Total & $\mathbf{1 2}$ \\
\hline
\end{tabular}

Interviews were carried out by the lead author in a place chosen by each interviewee and ranged from 30 minutes to more than an hour in duration. All interviews were audio recorded and transcribed. Thematic analysis of the interviews by coding used NVivo 12 Plus software and employed both a top down deductive approach based on the research aim, and a bottom up inductive approach identifying themes that "represent some level of patterned response or meaning within the dataset" (Braun \& Clarke 2006). Coding was a recursive process, which started at the interview stage and continued throughout transcription and analysis. The interviews were a rich source of data, running to almost 75,000 words of transcription in total with individual interviews ranging from three to over ten thousand words. 


\section{Results}

The 12 interviewees represented environmental and mining regulators, consultants and corporate and site environmental managers from mid-tier mining companies (Table 1). All had more than nine years professional experience. In compliance with the ethics approval for this research, a detailed profile of interviewees is not provided here.

As indicated previously, the interviews proceeded in a free-flowing conversational manner without a linear question sequence. Accordingly, the results are presented in relation to key themes identified in the responses we received. We have grouped these into two core sub-sections devoted to the analysis of how EIA and mine closure planning is integrated in Western Australia, and how this facilitates effective early MCPs respectively. We divide each subsection into smaller components based on the positive aspects of integration, followed by key issues identified and opportunities for improvement that were described. In presenting our results, we commence with interviewee insights and then reflect further upon these in relation to published material along with illustrative quotations from individual interviewees. A final subsection discusses aspects that were absent from the interviews, but which are identified as important in the published literature, along with some of our own reflections on these in the Western Australia context.

\subsection{Integration of environmental impact assessment and mine closure planning in Western Australia}

\subsubsection{Positive aspects}

All 12 interviewees identified positive aspects of integration arising from the process synergies between EIA and mine closure planning in Western Australia. ElA was described by one consultant as " $a$ small but vital piece" for mine closure planning.

The interviews identified similar processes that were integrated (or at least interrelated) for the acquisition of high-quality data, which informs risk assessment, enables early identification of fatal flaws, and leads to the development of management and mitigation strategies. Integration of mine closure planning into the approvals process was considered an effective tool for mine design and planning. Process synergies for efficiency were also identified by combining baseline environmental data collection with closure data collection. Some illustrative comments were:

"Oh, risk is an integral part of the mine closure planning... [for] any company who is doing it properly, risk should drive the whole process. The reason you do an EIA is that you've got a project there that triggers sensitive areas, or you've got a risk to the environment."

"Baseline information is critical. This is where EIA plays the part in mine closure, we need to understand the information about groundwater, we need to understand the material characterisation... They're integral. There's no doubt about it."

"We were [previously] developing mine closure plans, [that were] very conceptual, really tied to nothing and lacked sound scientific basis. Through evolution, that has now changed a hell of a lot with the mine closure planning guidelines now being brought forward into the earlier assessment. It's not perfect, but I think we've come a long way in a very short period."

The identification of key mine closure risks and flagging fatal flaws at the project approval stage was emphatically asserted as essential by everybody interviewed and was considered the most important aspect of integration with EIA, although the risk assessment process was questioned by one consultant.

All of the participants were asked their thoughts regarding improved integration and the responses were mixed. All the environmental managers and one consultant thought that no specific improvements were required as the current Western Australia framework works well, process synergies and early consideration 
of mine closure benefits operational strategies for closure and enables a more efficient approvals process and will improve over time.

One environmental manager described the legislative framework as well-integrated, where mine closure is back-influencing the EIA approvals process through recognition of poor closure outcomes due to a lack of knowledge and unrealistic or poorly defined approval conditions in the past. Learning and continual knowledge development being the key to improving mine closure outcomes. Another stated that integration and consultation was important to prevent lost opportunities for mine closure.

Beneficial integration of mine closure within and between different parts of the business at the EIA stage was noted by an environmental manager and this reflects the ICMM (2019) view of mine closure integrated into the core of the business.

"With this whole integration process, it allows good dialogue between all parts of the business... and to give [the regulators] an update on where things are at. That's very common with DMIRS, probably not so much with the EPA."

"[The] mine planning guys are more aligned, engaged and involved in the process. I think the next step is to [get] the senior executives engaged a bit more. It's getting more embedded at the operational level and then percolating its way up the management tree."

"It's being driven internally and it's also a case of educating."

The integration between EIA and early mine closure planning was seen as more valuable for mines with a short life due to imminent closure, or brownfields projects or revised proposals that had a greater level of baseline data to better inform a more detailed MCP.

\subsubsection{Negative aspects}

The regulators described the common guidance (DMP \& EPA 2015) and agency collaboration as essential to ensure acceptable levels of residual risk should a proposal go ahead. However, the consultants identified a lack of consistency and resultant delays that stem from the different motivation of the two agencies, in particular the strategic environmental focus of the EPA versus the operational risk and feasibility focus by DMIRS.

"In theory they are [integrated], in practice they're not... It should flow through, but it doesn't... That's a failure of the framework and it just needs to be tweaked."

Two of the consultants described the Guidelines as a "table of contents" and emphasised the limitations of generic guidance. The issue of guidance is an important one. Waldeck et al. (2003) identified the significant influence of non-formal guidance on the practice of EIA consultants and a resultant enhancement in the effectiveness of EIA, and McCullough et al. (2018) state that the certainty of closure outcomes is reliant on the clarity of regulatory requirements.

Not everybody agreed that EIA was integrated with mine closure planning. One environmental manager thought the EIA and mine closure planning was only 50\% integrated and only because of the process synergies of EIA outcomes informing MCP risk evaluation. One consultant described the system as interlinked with similar components, rather than integrated:

"The changes to require a mine closure plan to be put forward with a new or amended [proposal] is a step in the right direction but I don't know that it really influences a lot."

\subsubsection{Opportunity to do better}

All of the regulators and one of the consultants identified potential benefits that could arise from lateral integration and a more strategic and/or regional approach to mine closure planning. Strategic planning is not currently realised within the integrated legislative framework of Western Australia. 
Mine closure planning benefits from cooperation. As Doelle and Sinclair (2006) point out in relation to public participation in EIA, there "simply is no way to legislate cooperation and creative problem solving" (p. 192). The regulators provided good examples of collaborative rehabilitation efforts in the Goldfields and the Pilbara, although commercial sensitivities make this difficult to advocate. The regulators also highlighted the value of information sharing, collaboration and knowledge development around mine closure issues cofunded by government and industry under the umbrella of independent organisations such as the Western Australian Biodiversity Science Institute (WABSI) and the Centre for Mine Site Restoration (CMSR). Such initiatives were considered as a necessary complement to regulatory enforcement and compliance strategies. Another consultant thought that the 'polluter pays' position was too focused, resulting in mines devising independent closure solutions, whereas achievable, effective closure may be better addressed collaboratively with a regional plan in mind.

"Where [research groups] like WASBI and government can help out... [is to provide] guidance with clear achievable outcomes and a way to get there."

\subsubsection{Comparison with published accounts}

In theory, integration of EIA with other forms of impact assessment or environmental management processes has the potential to improve environmental outcomes and better inform the decision-making process (Scrase \& Sheate 2002). A multi-disciplinary approach can provide a holistic view and improve the identification of knowledge gaps, alternatives and cumulative impacts (Duncan 2008; Orenstein et al. 2010; Geneletti 2014). Potential pitfalls to integration result from the complexity of integrating multiple assessments, poor collaboration and potentially unbalanced results whereby important issues are masked by the promotion of others. A clear focus developed early at the scoping stage is therefore important for an effective integrated assessment (Scrase \& Sheate 2002; Tajima \& Fischer 2013; Greig \& Duinker 2014). This could be realised from inclusion of mine closure planning within EIA scoping in the Western Australia framework, whereby the impact assessment terms of reference are defined from preliminary information. One regulator described the scoping process as detailed and consultative between the agencies and where specific mine closure aspects can be incorporated into EIA if required.

The importance of early integration to improve planning, decision-making and accountability is central to industry best practice guidance (DIIS 2016; ICMM 2019) and was emphasised in submissions to the Senate (Environment and Communications References Committee 2019). Industry best practice identifies sound scientific knowledge and quality data as the basis for effective risk assessment and a requirement of evidence-based decision-making (DMP \& EPA 2015; DIIS 2016). Risk assessment and risk management is essential for effective mine closure planning and written throughout the regulatory guidelines (DMP \& EPA 2015; Amirshenava \& Osanloo 2018; EPA 2018; ICMM 2019). Although EIA has traditionally focused on operational risk rather than closure risk, the assessment, prediction, management and mitigation of risk and minimising liabilities is core to both (Hyett 2010). The evaluation and mitigation of risk that feeds directly into closure planning strategies, such as the identification of flora or fauna conservation issues, habitat remediation strategies, or identification of acid mine drainage (AMD) potential, was considered the most important aspect and most widely recognised form of integration in the interviews.

These international perspectives from the literature resonate with the views of the Western Australian practitioners. It is clear from the interviews that the regulators and environmental managers believe that there is integration between EIA and mine closure planning at the project approval stage, which is more broadly developed than simply the outcome of EIA informing mine closure plans, and where mine closure has also been back-influencing EIA and the approvals process. The consultants were a little more sceptical, and identified problematic disconnection between the regulatory agencies, and one consultant did not believe that EIA and MCPs are integrated but are interrelated instead. 


\subsection{Current effectiveness of early mine closure plans from integration with environmental impact assessment}

\subsubsection{Positive aspects}

All interviewees agreed that bringing mine closure into the conversation early was essential to deliver better outcomes which is consistent with international expectations (e.g. ICMM 2019). Early inclusion fosters discussion between industry and regulators, and several consultants and environmental managers described wider beneficial engagement around mine closure across different levels of the business, for example financiers, planners and mine managers as well as environmental managers. This cultural shift was exemplified by the inclusion of closure targets in the performance indicators of mine managers for at least one of the mid-tier companies represented by the participants, and the inclusion of key performance indicators for closure were also described in recent submissions to the Senate (Environment and Communications References Committee 2019, p. 43). Cultural development and discussion are an important step towards the vision of integrated mine closure and the lifecycle approach put forward by the ICMM (2019) and is evidence of improvement of mine closure effectiveness in the current framework. Although most participants noted that the culture around mine closure was at least partially changing, it is yet to be embedded in industry, as one environmental manager said, "When you say there's a mine closure plan [you genuinely get the comment], 'but why we're not closing'... We don't raise the mine closure title too many times. We say, 'this is a condition on a tenement'."

The integration of EIA and mine closure planning is the first part of the wider framework of mine closure that includes annual environmental reporting, triannual updates to the mine closure plan and financial provisioning and as stated by one regulator 'just requiring mine closure planning at the front by itself won't deliver'. Other illustrative comments include the following:

'The thing that I noticed most when we brought out the guidelines in 2011 was the feedback we were getting mostly from consultants and occasionally from industry, was it was making people think about it upfront.'

'Without having mine closure planning at the [start] it would be extremely difficult to deliver good closure outcomes.'

'What controls you put in early on, will affect your mine closure plan at the end. If you don't get it right from the start you're not going to do well at the end.'

'The whole life cycle planning I think now considers closure as part of its core. If you don't know how to close an operation, why do you start?'

Several of the regulators and consultants described the importance of early planning to develop more costeffective closure options. Early mine closure planning enables early decisions to be made for the design and scheduling of components such as infrastructure placement and landform development that can be costly and time consuming to rectify later (Nehring \& Cheng 2016; McCullough et al. 2018) and that can have implications for post-mining land use (Howard et al. 2014; ICMM 2019). As said by regulators:

"Not only is there a good environmental outcome by doing that [starting early] but there's a really good economic efficiency for the companies to drive that."

"Having [mine closure] as part of the EIA is definitely is a good idea because if it's done well it can influence the operations positively and save them headaches down the track and that would be by far the most critical element."

Opportunities to trial rehabilitation alongside mine operations was described by both consultants and regulators:

"Progressive rehab is not just greening up brown dirt it's research... so you're not starting your 10 years of monitoring once everything's shut down, hopefully you were doing 
things here and there that is going to help give you that cumulative evidence that government is going to want to sign off on"

The benefit of undertaking closure studies as early as possible provides time for adaptive management and refinement of rehabilitation techniques and allows options to be identified and trajectories for closure criteria to be defined, considered and built into the mine plan (Stambolie 2017; DIIS 2016).

\subsubsection{Negative aspects}

A key determinant on the effectiveness of integration of EIA and mine closure planning, and the development of effective early MCPs, is the experience, enthusiasm and strategic view of key facilitators, including proponents, consultants and regulators. All of the participants demonstrated a personal passion for effective mine closure.

The interview responses identified instances of poor early MCPs due to short-term views of the mine planners, either from a company strategy to on sell the deposit, short-term performance indicators for the 'approvals' team which ignores the rest of the mine's lifecycle, or a lack of experience and/or capability within both industry and the regulators. This was reflected throughout the interview responses as the following examples attest.

"Relying on individuals is a problem. Because from one year, one decade to another, that will not be consistent. So that's a flawed system. You can't rely on [good intentions] because at the end of the day a business is a business and they will do the minimum amount they require."

"I think the framework works at the moment. The concerns that I hear are about people not understanding the framework, [or] the regulators not applying the framework as it's supposed to."

"You've got junior people assessing [the MCP], very few of those people... have actually had practical hands on experience... There's very few who successfully closed a mine and have gone through that whole experience."

Concern was raised by two of the consultants regarding the typical situation on a mine site, where the role of the mine closure planner is often left with the site's environmental managers. Mine closure is multifaceted and multi-disciplinary and integration within the mine's lifecycle from the project approval stage requires a skilled coordinator and support from all parts of business to achieve efficient and effective outcomes (ICMM 2019).

"There's a mixture [of capabilities] and I think there's always going to be a mixture. It's down to the environmental passion of the company and it usually comes from the top."

"It all comes down to people's passion and interest because [information sharing, and collaboration is] generally above and beyond your core business or your core job description."

Consultation with the local community for closure has not usually commenced at the project approval stage, although in Western Australia this was discussed as partly due to remote locations and a small number of stakeholders, or stakeholder apathy or disillusionment from earlier consultations which was identified during the interviews. Early stakeholder engagement is necessary to identify acceptable EIA and mine closure outcomes and achieve project legitimacy (Morrison-Saunders \& Pope 2013; Morrison-Saunders et al. 2016) but is typically inadequate and occurs towards the end of the project for mine closure due to fears of unrealistic expectations, and similar to EIA and closure planning integration, is largely dependent upon the determination and aptitude of the facilitators (Lamb \& Coakes 2012; Moffat \& Zhang 2014; Kabir et al. 2015).

The consultants raised issues with transparency and enforcement that negatively impact the incentive to prepare effective early MCPs. The 2015 revision of the Guidelines indicates the level of detail required at the project approval stage (Table 2), which suggests several closure aspects should be 'well advanced' or 
'detailed', but this may not be not be required for an MCP to be approved as the level of detail required is commensurate with perceived risk (DMP \& EPA 2015, p. 4). The regulators describe the risk-based approach to determining acceptable content:
"I think probably there needs to be more of a standard around what is acceptable upfront. For myself, generally I'm okay not necessarily receiving a closure plan with EIA on sites that aren't high risk. What I'm more interested in is have they done their analysis properly to identify what their key risks are, and have they identified how they're going to avoid them and manage them through the life of mine."

"Benchmarking... [in the] Goldfield's it's quite easy to do because there's so many examples, but we are going to expect a higher level in that MCP with that mining proposal and that's not us being inconsistent that's us being risk-based."

Table 2 Indication of the level of closure detail required in a mine closure plan (MCP) at the project approval stage (DMP \& EPA 2015)

\begin{tabular}{|c|c|}
\hline Closure aspect & Level of detail \\
\hline Stakeholder engagement & $\begin{array}{l}\text { Consultation continues - proposed end land use options } \\
\text { refined and plans for closure discussed. Ongoing } \\
\text { consultation strategy defined }\end{array}$ \\
\hline Post-mining land use & Well advanced \\
\hline Closure objectives & Well advanced \\
\hline Completion criteria & Qualitative \\
\hline $\begin{array}{l}\text { Collection and analysis of closure } \\
\text { data }\end{array}$ & $\begin{array}{l}\text { Development of the operation with rehabilitation and } \\
\text { closure in mind (e.g. waste landform design and location) }\end{array}$ \\
\hline Materials characterisation & $\begin{array}{l}\text { Detailed material characterisation including geochemical } \\
\text { and physical properties, volumes and proposed uses }\end{array}$ \\
\hline $\begin{array}{l}\text { Identification and management of } \\
\text { key environmental issues }\end{array}$ & $\begin{array}{l}\text { Closure-based risk assessment conducted, and mitigation } \\
\text { strategies incorporated into mine design }\end{array}$ \\
\hline $\begin{array}{l}\text { Closure implementation and } \\
\text { monitoring plans }\end{array}$ & Well advanced \\
\hline Financial provisioning assumptions & $\begin{array}{l}\text { Process, methodology and assumptions transparent and } \\
\text { verifiable and updated to reflect increased knowledge of } \\
\text { the operation }\end{array}$ \\
\hline
\end{tabular}

The lack of transparency around the level of detail required also extends to the confidential comments provided in a letter by DMIRS to the proponent indicating issues to be addressed by the next revision of the MCP. The lack of visibility around this information suggests to an onlooker that substandard approvals can be accepted. However, as one regulator stated, "I try to tell people to bear that in mind. That's not saying that's our standard, the company will know what we need to be fixed. And at this point in time we're not able to make our approval letters public."

In general, most consultants agreed that early MCPs lack detail and opinion was divided as to whether this was an issue, as representatives from all professions felt that a conceptual early MCP was sufficient for a low risk project and all the consultants and two of the regulators believe that the ongoing refinement, rather than a definitive early MCP, was important. However, one consultant felt that simple and effective closure investigations such as erosion modelling and material balances aren't being adequately addressed at the project approval stage, potentially allowing projects to commence without sufficient rehabilitation resources. A lack of detail and excessive protection of confidential information means claims in an MCP 
cannot be independently verified, reducing transparency and potentially increasing risk. As one consultant said:

"That's why the closure plans are useless. The [lack of] information in terms of how they cost it. You don't have the footprint you don't have the volumes. If the closure plan was required to put how much concrete on the ground and how much steel is in there somebody could do a true liability estimate... as an independent review on what the closure liability is."

The level of detail for the available information can be related to the usefulness of the early MCP. One regulator said, "I think the EIA will have a different degree of impact on the closure outcomes for greenfields projects... I think at the revised proposal stage will be much more accurate and precise. And closure plans and things like that are much more useful." However, the regulators and consultants describe considering the balance between the level of detailed closure data required and the cost of obtaining it, considering the early project stage before income is generated by production. One consultant was concerned regarding the disconnect between EIA at the beginning of a mine life and mine closure at the end, as "No one's actually thinking about how are we going to close it in 20 years' time".

Two of the regulators acknowledged enforcement issues, attributed to a lack of bonds or the lack of clearly defined limits for rehabilitation, such as exists such as for licencing of emissions.

"It's really hard to regulate rehab, we're not cut and dry. You have to build a really good relationship with the proponent and work with them because we can't stand behind some licence conditions you didn't meet yet which up the road you can."

"We have to really work with the company or we're going to fail miserably. We have to encourage and coerce and incentivise as much as we can because we don't have the ransom of, well you're not going to get your money back."

One consultant was emphatic regarding the lack of enforcement from the regulators, describing them as 'toothless tigers'. Lack of enforcement was identified by Scrase and Sheate (2002) as reducing the benefit of the environmental assessment process. Two other interviewee comments resonated with this perspective:

"The key thing early on is, 'I commit to this'. But if you're not going to hold me accountable then why am I going to rush?"

"What's the consequence to it? There is none. They're not fined. I've never heard anybody being issued [a fine]. It's left too much to self-regulation. Self-regulation doesn't work."

\subsubsection{Opportunity to do better}

A number of alternate enforcers to enable effective early mine closure planning were identified by one of the regulators:

"We did an evaluation project... a few years ago and we identified that the companies who are achieving the best outcomes are usually the ones where there's another requirement. For example, they're linked to the New York Stock Exchange where they have to report environmental liability... or in other cases where there's a lot of community pressure [such as a high value asset] and companies see that social license aspect... or where conditions are quite prescriptive companies will... achieve those outcomes because they know that the regulators are monitoring that every year."

Two consultants were clear about the effectiveness of early MCPs, suggesting, however that having a slightly different focus would be more appropriate:

"[Early MCP] is effective because it's a closure strategy. It's not mine closure plan because it's conceptual... Whereas your mining proposal, I've got designs for landforms 
and plant that I can put in my closure plan... It will change but at least we can develop closure criteria against that. Which you can't really do at an early stage."

This is comparable to the high-level 'closure vision' rather than more detailed closure principles and objectives endorsed by the ICMM $(2019$, p. 17). However, most of the consultants and environmental managers observed a trajectory of improvement with the mine closure framework:

"Each year they are getting a little bit more stringent with the mine closure plan delivery at the Mines Department. The criteria is tightening up as it should, because it's improvement of the plan."

\subsubsection{Comparison with published accounts}

Literature regarding the effectiveness of mine closure planning in Australia based on empirical studies is limited and mine closure issues, when addressed, are typically within peer reviewed conference papers (such as this annual international Mine Closure Conference) or industry publications (such as the AusIMM Bulletin).

Early mine closure planning is important to minimise the environmental, financial, social and legal liabilities of mine closure, and these liabilities are an important consideration for potential financiers at the project approval stage (Sweeting \& Clark 2000; Banhalmi-Zakar \& Larsen 2015). The early inclusion of mine closure planning was described during the interviews as fundamental to the effectiveness of early MCP through the early identification of risks and fatal flaws to guide decision-making, obtaining closure data that may otherwise be lost, and ensure efficient mine planning that considers closure requirements.

Early identification of risk and liabilities were unequivocally considered the most important outcome from the integration of EIA and mine closure planning. Particularly in the context of potentially irreversible early decisions that can be environmentally damaging, costly and affect post-mining land use opportunities (Gorey et al. 2014; Keith \& van Rensburg 2017). Mine closure activities and rehabilitation monitoring are expensive and at risk of neglect if left to the end of a mine life when it is least profitable (DIIS 2016). Mine closure can be unpredictable (Laurence 2006), but all the participants considered that a pragmatic approach to early mine closure planning is necessary to balance the desire for detailed closure design with the financial burden of mining projects in the early stages prior to income generation.

Integration that can lead to more effective mine closure planning was evidenced in the development of a culture of mine closure described for wider parts of the business and knowledge development, learning from past mistakes and even back-influencing the approvals process to achieve better outcomes. Learning and knowledge development delivers effectiveness by broadening acceptance and understanding with stakeholders, transforming standards and practices and improving outcomes (Sánchez \& Mitchell 2017; Cruz et al. 2018; Pope et al. 2018; ICMM 2019).

Although the integration of EIA and mine closure planning was not unanimously accepted by the interviewees, the early inclusion of MCPs, even as a closure strategy or vision rather than a definite plan, was widely considered a positive step towards effective mine closure planning and starts the conversation (DIIS 2016). The potential for integration to increase effectiveness and reduce costs through efficiency planning identified by Nehring \& Cheng (2014) was mentioned in terms of the importance of early landform design by one of the consultants and by the regulators. A lifecycle approach to mine closure planning, that starts at concept and is continued throughout the mine life, is internationally considered best practice (Mudd 2010; Loch \& Howard 2018; ICMM 2019). The issues identified with the integrated framework in Western Australia such as poor alignment between the lead agencies and a lack of guidance and enforcement, reflect the potential integration issues identified in the literature such as duplication of effort or poor collaboration (Scrase \& Sheate 2002; Tajima \& Fischer 2013; Greig \& Duinker 2014).

The importance of key facilitators with enthusiasm for EIA and mine closure is perhaps not surprising. Integration occurs best when managed by key, driven facilitators (Sroufe 2017) and ICMM guidance (2019, p. 64) defines the role of a closure champion that is critical to lead and engage the closure process. Anglo American's Integrated Closure Planning System (ICPS) emphasises the integration and engagement of people 
as being essential to facilitate integrated mine closure in a corporation, with processes and technology only capable of achieving $40-60 \%$ of effectiveness (Grant \& Lacy 2016).

Transparency and enforcement were described as weak by the consultants. Transparency, including transparency of the decision-making process, financial assurance, and mine closure methods with proposed outcomes should be accessible and comprehensible to allow external evaluation, build accountability and ensure a consistent approach (Morrison-Saunders \& Bailey 2000; McHenry et al. 2015; ICMM 2019). Adequacy of regulation and transparency were two of the matters tabled for investigation by Senate and some submissions highlighted concern regarding the clarity around closure standards and financial provision (Environment and Communications References Committee 2019) and clear guidance from the regulators is recognised as important to minimise delays to the approval process (McCullough et al. 2018). However, the interview described a lack of clarity regarding expectations, inconsistency within and between the lead agencies for approval assessments of MCPs, and a lack of guidance in the Guidelines, resulting in delays to the approval process.

\subsection{Other aspects/authors' thoughts}

One topic that we noted was somewhat conspicuous in its absence from the interviews was that of 'sustainability'. EIA and mine closure planning, in principle, should support sustainable development (IAIA 1999; Kwasniak 2010; Morrison-Saunders et al. 2016). More specifically, the concept of sustainable development is a core consideration for mine closure planning that is recurrent through Australian and international best practice guidelines (DIIS 2016; ICMM 2019). Sustainability in mine closure revolves around the concept of a self-sustaining and resilient acceptable end land use that provides socio-economic benefits to the local region (ICMM 2019). These principles align with the Sustainable Development Goals of the United Nations (United Nations 2015) and help guide a company's social licence to operate (Parsons \& Moffat 2014; Gehman et al. 2017; ICMM 2019). We had anticipated that interviewees might discuss the topic of sustainable development directly and explicitly, but this was not the case. As one consultant reflected:

"Social license only plays a part for those that have reputation sensitivity and that would be restricted in this State to large players. Nobody else is reputation sensitive. They're so low under the radar that it's not a consequence to them."

We observe that specific discussion of 'sustainability' is not common in Western Australia, although some 15 years ago at the time in which the State Government established the State Sustainability Strategy (Government of Western Australia 2003) it was an explicit topic of discussion. The recent Senate hearings on the environmental, social and economic benefits and impacts of mine rehabilitation (Environment and Communications References Committee 2019) also excluded the term sustainability. Thus, our interviewees are consistent with current trends in this regard. It means that sustainability concepts need to be interpreted in relation to other terms and topics such as that of social licence.

One of the key drivers for the development of early closure plans and evaluation of financial assurances is the risk of early or unexpected mine closure (Haymont 2012; ICMM 2019). However, this wasn't raised in the interview discussions and may be a reflection of the positive mining outlook in the context of improved economic conditions following the mining downturn.

\section{Conclusion}

The aim of this research was to explore how the integration of EIA and mine closure planning facilitates effective MCPs at the project approval stage, since becoming a regulatory requirement following amendments to the Mining Act 1978 in 2011. The primary research was coded analysis of semi-structured interviews undertaken with 12 professionals with more than nine years' experience in the field of EIA and/or mine closure planning.

The mine closure practitioners were emphatic that the legislative and procedural change to 'force' early consideration of mine closure is considered to be important for risk identification and the development of 
effective MCPs. These perspectives are consistent with the goals of mine closure planning such as those espoused in the ICMM (2019) guideline for integrated mine closure. Other main findings are that:

- Early mine closure planning facilitates early discussion, broadens knowledge and cultural acceptance between different parts of the business, aids identification of key risks and fatal flaws, aids decision-making for mine planning, and enables investigations and trials to start early to maximise rehabilitation success.

- Strong areas of integration that currently exist between EIA and mine closure planning are the evaluation, prediction and mitigation of risk, collection of sound scientific knowledge, and in some cases the start of early and ongoing consultation to develop sustainable mining goals (although sustainable development was not explicitly mentioned in any of the interviews).

- The effectiveness of integration between EIA and mine closure planning is strongly dependent upon the drive and enthusiasm of key facilitators, and requires a collaborative approach.

- Key constraints on effective integration of EIA for mine closure planning are a lack of regulatory guidance and enforcement compounded by a lack of transparency of process and no financial disclosure requirements which hinders wider learning.

There were mixed views among the participants as to whether the integration of EIA and mine closure planning leads to effective MCPs at the project approval stage, or if it is even possible for early MCPs to be effective, as there is no empirical evidence to validate these assumptions. Nevertheless, overall our interviewees and the published guidance on mine closure planning are consistent in advocating for attempting early and sustained integration of EIA and MCP on the basis that it will enhance mine closure effectiveness in the long run. Thus, it remains as international best practice to at least strive to deliver.

In conclusion, we acknowledge that the integration of EIA and mine closure planning is a relatively new aspiration in Western Australia, given that the original joint Guidelines has only been in place since 2011. Despite the newness of the field, there is clear evidence that progress has and continues to be made to align mine closure planning in Western Australia with national and international best practice guidelines. This progress includes development of the mine closure culture and improved knowledge base. However, the current framework faces issues of transparency and enforcement, a lack of guidance and a strong reliance on key facilitators to deliver good closure outcomes, and therefore improvements could be made. Our findings lead us to pose some recommendations aimed at practitioners for enhancing mine closure integration in practice into the future as follows:

- Start the discussion early to integrate mine closure into all levels of the business and mine planning.

- Early consultation that commences during EIA data collection and continues throughout the mine life between all stakeholders (not just local government and the regulators) to identify opportunities and constraints for sustainable mine closure.

- Seek opportunities for meaningful collaboration such between regulators during EIA, or between companies or independent agencies such as WABSI to further knowledge and better use resources to improve mine closure outcomes.

- MCPs at the project approval stage should represent the closure 'vision' based on mitigation of key risks using sound science, becoming more refined as more information becomes available.

- Improve regulatory guidance around best practice mine closure planning and enforcement to ensure closure commitments are delivered.

- Improve transparency, within the regulatory process and for disclosure of MCPs to share knowledge and learnings. 
- Develop support for integration between EIA and mine closure planning, there are many benefits but currently this is reliant on the drive and enthusiasm of key facilitators.

Implementation of these suggestions does not necessitate legislative change or even necessarily any modification to mine closure guidance, but rather lie in the domain of professional practice.

Overall our research shows that the integration of EIA and mine closure planning can aid the provision of effective MCPs, and as identified by Morrison-Saunders et al. (2016), the two processes do go hand in hand. Current best practice guidelines emphasise the importance of an integrated framework for mine closure planning (ICMM 2019) and as the culture of mine closure planning is continuing to develop this may be better realised in the future.

\section{Acknowledgement}

The enthusiasm and participation of the environmental and mine closure professionals interviewed for this research is greatly appreciated.

\section{References}

Amirshenava, S \& Osanloo, M 2018, 'Mine closure risk management: an integration of 3D risk model and MCDM techniques', Journal of Cleaner Production, vol. 184, pp. 389-401, doi: 10.1016/j.jclepro.2018.01.186

Banhalmi-Zakar, Z \& Larsen, S 2015, 'How strategic environmental assessment can inform lenders about potential environmental risks', Impact Assessment and Project Appraisal, vol. 33, no. 1, pp. 68-72, doi: 10.1080/14615517.2014.941143

Bond, A \& Morrison-Saunders, A 2018, 'Environmental Impact Assessment and the quest for sustainable mining', in S Lodhia (ed.), Mining and Sustainable Development: Current Issues, Routledge Studies of the Extractive Industries and Sustainable Development, London, pp. 47-64.

Braun, V \& Clarke, V 2006, 'Using thematic analysis in psychology', Qualitative Research in Psychology, vol. 3, no. 2, pp. 77-101.

Canter, L \& Atkinson, SF 2010, 'Adaptive management with integrated decision making: an emerging tool for cumulative effects management', Impact Assessment and Project Appraisal, vol. 28, no. 4, pp. 287-297, doi: 10.3152/146155110X12838715793002.

Cruz, FB, Veronez, FA \& Montaño, M 2018, 'Evidence of learning processes in EIA systems', Impact Assessment and Project Appraisal, vol. 36, no. 3, pp. 242-252, doi: 10.1080/14615517.2018.1445177

Department of Industry, Innovation and Science 2016, Mine Closure - Leading Practice Sustainable Development Program for the Mining Industry, Commonwealth of Australia, Canberra.

Department of Mines and Petroleum \& Environmental Protection Authority 2009, Memorandum of Understanding between the Department of Mines and Petroleum and the Environmental Protection Authority in relation to the referral of Mineral and Petroleum (Onshore and Offshore) and Geothermal Proposals, viewed 21 March 2019, http://www.epa.wa.gov.au/sites/ default/files/Publications/EPA-DMP-MOU-290709.pdf

Department of Mines and Petroleum \& Environmental Protection Authority 2015, Guidelines for Preparing Mine Closure Plans, Department of Mines and Petroleum, East Perth.

Doelle, M \& Sinclair, AJ 2006, 'Time for a new approach to public participation in EA: promoting cooperation and consensus for sustainability', Environmental Impact Assessment Review, vol. 26, pp. 185-205.

Duncan, R 2008, 'Problematic practice in integrated impact assessment: the role of consultants and predictive computer models in burying uncertainty', Impact Assessment and Project Appraisal, vol. 26, no. 1, pp. 53-66, doi: 10.3152/146155108X303931.

Environment and Communications References Committee 2019, Rehabilitation of mining and resources projects as it relates to Commonwealth responsibilities, Commonwealth of Australia, Canberra.

Environmental Protection Authority 2018, Environmental Impact Assessment (Part IV Divisions 1 And 2) Procedures Manual, Environmental Protection Authority, Perth.

Geneletti, D 2014, 'Integration of impact assessment types improves consideration of alternatives', Impact Assessment and Project Appraisal, vol. 32, no. 1, pp. 17-18, doi: 10.1080/14615517.2013.872846.

Gehman, J, Lefsrud, LM \& Fast, S 2017, 'Social license to operate: Legitimacy by another name?', Canadian Public Administration, vol. 60 , no. 2 , pp. 293-317.

Grant, CD \& Lacy, HWB 2016, 'Developing Anglo American's integrated closure planning system requires people, process and technology working together', in AB Fourie \& M Tibbett (eds), Proceedings of the 11th International Conference on Mine Closure, Australian Centre for Geomechanics, Perth, pp. 581-594.

Greig, L \& Duinker, P 2014, 'Strengthening impact assessment: what problems do integration and focus fix?', Impact Assessment and Project Appraisal, vol. 32, no. 1, pp. 23-24, doi: 10.1080/14615517.2013.872849.

Gorey, P, Morrison-Saunders, A, Doepel, D, Mtegha, DH \& McHenry, MP 2014, 'Dealing with mining legacies: from bonds to a central mining rehabilitation fund in Western Australia', in IM Weiersbye, AB Fourie \& M Tibbett (eds), Proceedings of the Ninth International Conference for Mine Closure, Australian Centre for Geomechanics, Perth.

Government of Western Australia 2003, Hope for the Future: The Western Australian State Sustainability Strategy, Perth, viewed 18 December 2008, http://www.nrm.wa.gov.au/media/19609/state_sustainability_strategy_2003.pdf 
Guest, G, Bunce, A \& Johnson, L 2006, 'How many interviews are enough? An experiment with data saturation and variability', Field Methods, vol. 18, no. 1, pp. 59-82, doi: 10.1177/1525822X05279903

Haymont, R 2012, 'Critical analysis and mine closure: why do things still go wrong in a swirl of feasibility, regulation and planning?', in AB Fourie \& M Tibbett (eds), Proceedings of the Seventh International Conference on Mine Closure, Australian Centre for Geomechanics, Perth, pp. 39-48.

Howard, B, Pershke, D \& Jones, M 2014, 'Achieving better mine closure outcomes for less money', Proceedings of the Life-of-Mine 2014 Conference, The Australasian Institute of Mining and Metallurgy, Melbourne.

Hyett, D 2010, 'Environmental risk assessment in environmental impact assessment - optional or mandatory?', The Role of Impact Assessment in Transitioning to the Green Economy, 30th Annual Meeting of the International Association for Impact Assessment, 6-11 April 2010, Geneva.

International Council on Mining and Metals 2019, Integrated Mine Closure Good Practice Guide, 2nd edn, London.

International Association for Impact Assessment 1999, Principles of Environmental Impact Assessment Best Practice, International Association of Impact Assessment and the Institute of Environmental Assessment.

Kabir, SMA, Rabbi, F, Chowdhury, MB \& Akbar, D 2015, 'A review of mine closure planning and practice in Canada and Australia', World Review of Business Research, vol. 5, no. 3, pp. 140-159.

Keith, A \& van Rensburg, F 2017, 'Reimagining mine closure and rehabilitation', Aus/MM Bulletin, April 2017, The Australasian Institute of Mining and Metallurgy, Melbourne.

Kolhoff, AJ, Runhaar, HAC \& Driessen, PPJ 2009, 'The contribution of capacities and context to EIA system performance and effectiveness in developing countries: towards a better understanding', Impact Assessment and Project Appraisal, vol. 27, no. 4, pp. 271-282, doi: 10.3152/146155109X479459

Kwasniak, AKL 2010, 'Use and abuse of adaptive management in environmental assessment law and practice: a Canadian example and general lessons', Journal of Environmental Assessment Policy and Management, vol. 12, no. 4, pp. 425-468, doi: $10.1142 / \mathrm{S} 1464333210003723$

Lamb, K \& Coakes, S 2012, 'Effective social planning for mine closure', in AB Fourie \& M Tibbett (eds), Proceedings of the Seventh International Conference on Mine Closure, Australian Centre for Geomechanics, Perth, pp. 627-639.

Laurence, D 2006, 'Optimisation of the mine closure process', Journal of Cleaner Production, vol. 14, pp. 285-298, doi: 10.1016/j.jclepro.2004.04.011

Leech, BL 2002, 'Asking questions: Techniques for semi-structured interviews', Political Science and Politics, vol. 35, no. 4, pp. 665-668, viewed 1 April 2019, https://www.cambridge.org/core/journals/ps-political-science-andpolitics/article/asking-questions-techniques-for-semistructured-interviews/E1CF8B87E87F36611AEC4D4A20468DE5

Loch, RJ \& Howard, EJ 2018, 'Material characterisation - avoiding unnecessary costs and failures', From Start to Finish: Life of Mine Perspective, Spectrum 24, The Australasian Institute of Mining and Metallurgy, Melbourne.

McCullough, CD, Harvey, B, Unger, BCJ, Winchester, S, McCarthy, B \& Coetzee, J 2018, 'From start to finish - a perspective on improving sustainable development aspects of life-of-mine practices', From Start to Finish: Life of Mine Perspective, Spectrum 24, The Australasian Institute of Mining and Metallurgy, Melbourne.

McHenry, MP, Morrison-Saunders, A, Gorey, P, Sequeira, AR, Mtegha, H \& Doepel, D 2015, 'Puzzled: navigating extractive policy information jigsaws for best practice and transparency', The Extractive Industries and Society, vol. 2, pp. 401-405.

Minister for Mines and Petroleum 2012, Petition No. 143 - Environmental Legacy of Mining, [letter to the Standing Committee on Environment and Public Affairs.

Moffat, K \& Zhang, A 2014, 'The paths to social licence to operate: an integrative model explaining community acceptance of mining', Resources Policy, vol. 39, pp. 61-70.

Morrison-Saunders, A \& Bailey, M 2000, 'Transparency in environment impact assessment decision-making: recent developments in Western Australia', Impact Assessment and Project Appraisal, vol. 18, no. 40, pp. 260-270.

Morrison-Saunders, A \& Pope, J 2013, 'Mine closure planning and social responsibility in Western Australia: recent policy innovations', in J Wiertz (ed.), 2nd International Conference on Social Responsibility in Mining, Gecamin, Santiago, pp. 211-219.

Morrison-Saunders, A, McHenry, MP, Rita Sequeira, A, Gorey, P, Mtegha, H \& Doepel, D 2016, 'Integrating mine closure planning with environmental impact assessment: challenges and opportunities drawn from African and Australian practice', Impact Assessment and Project Appraisal, vol. 34, no. 2, pp. 117-128.

Mudd, GM 2010, 'The Environmental sustainability of mining in Australia: key mega-trends and looming constraints', Resources Policy, vol. 35, pp. 98-115, doi: 10.1016/j.resourpol.2009.12.001

Namey, E, Guest, G, McKenna, K \& Chen, M 2016, 'Evaluating bang for the buck: a cost-effectiveness comparison between individual interviews and focus groups based on thematic saturation levels', American Journal of Evaluation, vol. 37, no. 3, pp. 425-440, doi: 10.1177/1098214016630406

Nehring, M \& Cheng, X 2016, 'An investigation into the impact of mine closure and its associated cost on life of mine planning and resource recovery', Journal of Cleaner Production, vol. 127, pp. 228-239, doi: 10.1016/j.jclepro.2016.03.162

Nichols, LN 2019, 'Alt Resources to fast-track Bottle Creek gold mine into production within two years', Small Caps, viewed 27 March 2019, https://smallcaps.com.au/alt-resources-fast-track-bottle-creek-gold-mine-production-two-years/

Orenstein, M, Fossgard-Moser, T, Hindmarch, T, Dowse, S, Kuschminder, J, McCloskey, P \& Mugo, RK 2010, 'Case study of an integrated assessment: Shell's north field test in Alberta, Canada', Impact Assessment and Project Appraisal, vol. 28, no. 2, pp. 147-157, doi: 10.3152/146155110X498816

Otto, JM 1997, 'A national mineral policy as a regulatory tool', Resources Policy, vol. 23, pp. 1-7. 
Parsons, R \& Moffat, K 2014, 'Integrating impact and relational dimensions of social licence and social impact assessment', Impact Assessment and Project Appraisal, vol. 32, no. 4, pp. 273-282, doi: 10.1080/14615517.2014.936107

Pope, J, Bond, A, Cameron, C, Retief, F \& Morrison-Saunders, A 2018, 'Are current effectiveness criteria fit for purpose? Using a controversial strategic assessment as a test case', Environmental Impact Assessment Review, vol. 70, pp. 34-44, doi: 10.1016/j.eiar.2018.01.004.

Sánchez, LE \& Mitchell, R 2017, 'Conceptualizing impact assessment as a learning process', Environmental Impact Assessment Review, vol. 62, pp. 195-204.

Sánchez, LE, Silva-Sánchez, SS \& Neri, AC 2014, Guide for Mine Closure Planning, Instituto Brasileiro de Mineração, Lago Sul, viewed 19 March 2019, http://www.ibram.org.br/sites/1300/1382/00004091.pdf

Sánchez, LE \& Hacking, T 2002, 'An approach to linking environmental impact assessment and environmental management systems', Impact Assessment and Project Appraisal, vol. 20, no. 1, pp. 25-38, doi: 10.3152/147154602781766843

Saunders, M, Lewis, P \& Thornhill, A 2009, Research methods for business students, 5th edn, Pearson Education Limited, Harlow.

Scrase, JI \& Sheate, WR 2002, 'Integration and integrated approaches to assessment: what do they mean for the environment?', Journal of Environmental Policy \& Planning, vol. 4, pp. 275-294, doi: 10.1002/jepp.117

Sroufe, R 2017, 'Integration and organizational change towards sustainability', Journal of Cleaner Production, vol. 162, pp. 315-329, doi: 10.1016/j.jclepro.2017.05.180

Stambolie, T 2017, 'Rethinking mining studies in line with environmental requirements', Aus/MM Bulletin, February 2017, The Australasian Institute of Mining and Metallurgy, Melbourne.

Steadman, A \& Green, KP 2018, Fraser Institute Annual Survey of Mining Companies 2018, Fraser Institute, viewed 1 April 2019, https://www.fraserinstitute.org/studies/annual-survey-of-mining-companies-2018

Sweeting, AR \& Clark, AP 2000. Lightening the Lode: A Guide to Responsible Large-Scale Mining, Business and Policy Group, Conservation International, Washington.

Tajima, R \& Fischer, TB 2013, 'Should different impact assessment instruments be integrated? evidence from English spatial planning', Environmental Impact Assessment Review, vol. 41, pp. 29-37, doi: /10.1016/j.eiar.2013.02.001

United Nations 2015, Transforming our World: The 2030 Agenda for Sustainable Development, A/RES/70/1, viewed 17 October 2017, https://sustainabledevelopment.un.org/content/documents/21252030\%20Agenda\%20for \%20Sustainable\%20Development\%20web.pdf

van Asselt, MBA 2000, 'Integrated assessment', Perspectives on Uncertainty and Risk, Springer, Dordrecht.

Waldeck, S, Morrison-Saunders, A \& Annandale, D 2003, 'Effectiveness of non-legal ElA guidance from the perspective of consultants in Western Australia', Impact Assessment and Project Appraisal, vol. 21, no. 3, pp. 251-256, doi: 10.3152/147154603781766239 